\title{
Field surveys can improve predictions of habitat suitability for reintroductions: a swift fox case study
}

\author{
Zoe Paraskevopoulou, Hila Shamon, Melissa Songer \\ Graeme Ruxton and William J. McShea
}

\begin{abstract}
Reintroductions are challenging, and success rates are low despite extensive planning and considerable investment of resources. Improving predictive models for reintroduction planning is critical for achieving successful outcomes. The IUCN Guidelines for Reintroductions and Other Conservation Translocations recommend that habitat suitability assessments account for abiotic and biotic factors specific to the species to be reintroduced and, where needed, include habitat quality variables. However, habitat assessments are often based on remotely-sensed or existing geographical data that do not always reliably represent habitat quality variables. We tested the contribution of ground-based habitat quality metrics to habitat suitability models using a case study of the swift fox Vulpes velox, a mesocarnivore species for which a reintroduction is planned. Field surveys for habitat quality included collection of data on the main threat to the swift fox (the coyote Canis latrans), and for swift fox prey species. Our findings demonstrated that the inclusion of habitat quality variables derived from field surveys yielded better fitted models and a $16 \%$ increase in estimates of suitable habitat. Models including field survey data and models based only on interpolated geographical and remotely-sensed data had little overlap (38\%), demonstrating the significant impact that different models can have in determining appropriate locations for a reintroduction. We advocate that ground-based habitat metrics be included in habitat suitability assessments for reintroductions of mesocarnivores.
\end{abstract}

Keywords Field survey, habitat quality, habitat suitability, mesocarnivore, reintroduction, swift fox, Vulpes velox

Supplementary material for this article is available at doi.org/10.1017/So030605320000964

Zoe Paraskevopoulou and Graeme Ruxton University of St Andrews, Scotland, UK

Hila Shamon (Corresponding author, (1) orcid.org/0000-0001-5252-7013), Melissa Songer (10 orcid.org/0000-0001-5536-6315) and William J. McShea (D) orcid.org/0000-0002-8102-0200) Smithsonian Conservation Biology Institute, National Zoological Park, 1500 Remount Rd., Front Royal, Virginia 22630, USA. E-mail shamonh@si.edu

Received 4 July 2020. Revision requested 7 August 2020.

Accepted 21 September 2020. First published online 7 October 2021.

\section{Introduction}

R eintroductions remain challenging and success rates Rare low despite extensive planning and considerable investment of resources (Johnsingh \& Madhusudan, 2009; McCarthy et al., 2012). Improving predictive models for reintroduction planning is critical for increasing successful outcomes. Assessment of habitat suitability, defined as a habitat that can sustain a viable population over an ecological time frame (Kellner et al., 1992), is often the first step in reintroduction planning (IUCN/SSC, 2013). The IUCN Guidelines for Reintroductions and Other Conservation Translocations recommend that habitat suitability assessments account for abiotic and biotic factors specific to the target species and, where possible or when needed, should include habitat quality variables (IUCN/SSC, 2013), defined as factors that contribute to a species' fitness (Kellner et al., 1992).

Despite these recommendations many habitat suitability assessments for reintroductions do not include habitat quality (Cheyne, 2006). Habitat suitability models are often based on interpolated remote data (i.e. remotelysensed or interpolated geographical data) such as land cover, land use, topography and climate (Zielinski et al., 2010; Danzinger, 2011). The advantage of remote datasets is that in many cases they are freely available, reducing the costs of producing new data across large landscapes and seemingly eliminating the need for field surveys (Smith et al., 2016). However, some habitat variables cannot be measured by remote methods and field surveys may offer additional information that can improve the accuracy of predictions and potentially increase the probability of reintroduction success (Gil-Sánchez et al., 2011).

Including field surveys to determine habitat quality in habitat suitability assessments is particularly important for carnivore reintroductions because of the dependency of these species on prey densities and their susceptibility to human intolerance (Hayward \& Somers, 2009; Ripple et al., 2014). Although protocols for large carnivore reintroductions are relatively well established, mesocarnivore reintroductions vary in their inclusion of field surveys for habitat assessments (Gil-Sánchez et al., 2011; Manlick et al., 2017).

Several post-reintroduction habitat assessments for mesocarnivores have incorporated habitat quality variables, providing an opportunity to re-evaluate their importance. These studies have shown that interspecies competition and low-quality food resources reduce reintroduction success, suggesting that outcomes could potentially differ if 
these variables are considered prior to any release. For example, a kit fox Vulpes macrotis reintroduction in California failed because of insufficient densities of prey (Standley et al., 1992). Reintroduced American marten Martes americana had low survival rates in the presence of a sympatric carnivore, the fisher Pekania pennanti (Manlick et al., 2017). Another post-reintroduction study found that reintroduced fishers typically selected habitats in conjunction with the relative abundance of their prey, snowshoe hares Lepus americanus (Parsons et al., 2019), and selected marginal habitat in the presence of a sympatric carnivore, the bobcat Lynx rufus. These studies showed that mesocarnivores select habitats based on both prey and predator distributions, and that predictions could be improved if these habitat quality variables are considered when creating habitat suitability models (Parsons et al., 2019).

Here, we test the importance of including habitat quality variables based on field surveys in a habitat suitability assessment prior to the reintroduction of a mesocarnivore. We hypothesize that inclusion of the distribution and relative abundance of resources and threats will improve model predictions of habitat suitability. We tested our hypothesis using a habitat suitability assessment for the swift fox Vulpes velox, a mesocarnivore native to North American short grass prairies (Moehrenschlager et al., 2004). We validated our models using the locations of the fox in an established nearby population that has not expanded into the study area because of a natural barrier, a river.

\section{Study species and area}

Historically, the swift fox occurred in great numbers in the prairies of North America. By the early 1900s, populations were reduced to $<5 \%$ of their historical range, primarily as a result of rodent and predator control targeting the coyote Canis latrans and wolf Canis lupus (Moehrenschlager \& Sovada, 2016). Today, the swift fox has recolonized $40 \%$ of its historical range, and is presently categorized as Least Concern on the IUCN Red List (Moehrenschlager \& Sovada, 2016). Nevertheless, there remains a gap of $>300 \mathrm{~km}$ between the northern and southern portions of swift fox range and conservation measures are being undertaken to connect these populations (Fig. 1).

In the mid 1980s swift foxes were successfully reintroduced to Alberta and Saskatchewan, Canada, through over a decade of translocation efforts (Smeeton \& Weagle, 2000). This population has subsequently expanded into north-east Montana, with a resident population occurring north of the Milk River (Moehrenschlager \& Sovada, 2016; Fig. 1). Sightings of swift foxes south of the Milk River have been reported (Heather Harris, Montana Fish and Wildlife Parks, pers. comm., 2018), but no population has been established south of the river. Fort Belknap Indian Reservation

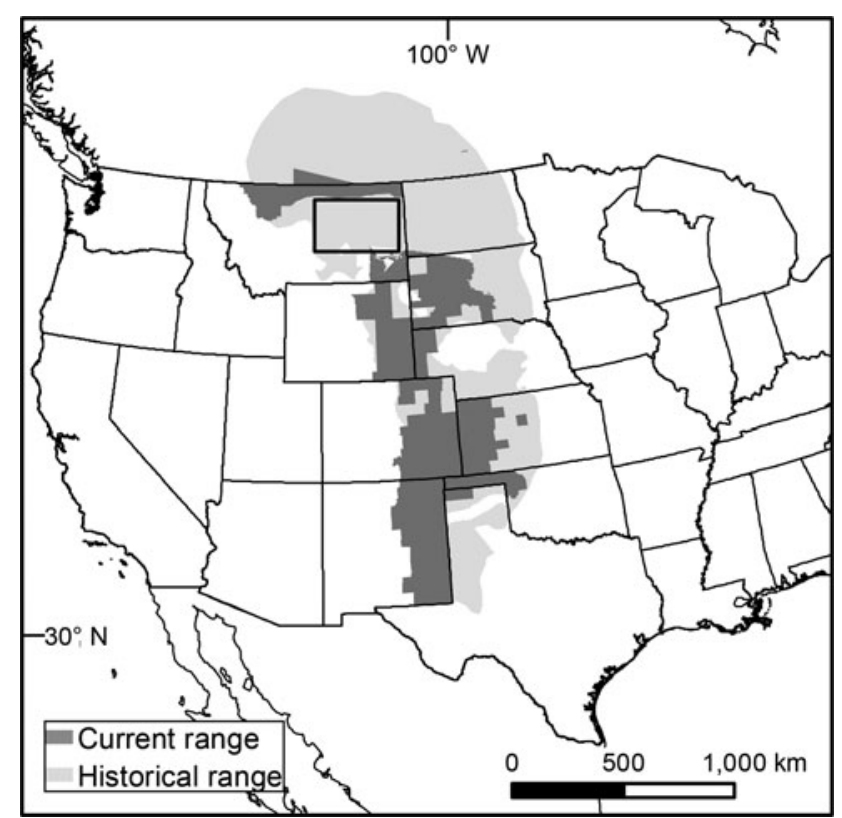

FIG. 1 Swift fox Vulpes velox historical and current range in the Great Plains of North America (adapted from Moehrenschlager \& Sovada, 2016). The rectangle indicates the gap between the northern and southern swift fox populations.

lies south of the Milk River within the gap in the swift fox range (Fig. 2). The Reservation is home to the Assiniboine and Gros Ventre Tribes, who are coordinating a swift fox reintroduction to their sovereign lands.

The study area is within the Northern Great Plains of North America in a short grass and mixed grass prairie, with ephemeral streams. Landownership is a mixture of tribal trust, and private and public lands, with cattle ranching as the primary land use. There are two rivers running west to east through the study area, the Missouri River to the south and the Milk River to the north (Fig. 2). The proposed $15,230 \mathrm{~km}^{2}$ reintroduction area lies between these two rivers. The work presented here is part of the feasibility assessment conducted prior to the swift fox reintroduction.

\section{Methods}

\section{Field surveys}

We surveyed three components of swift fox diet (Table 1) using camera traps (Lagomorpha spp.), track plates (Rodentia spp.) and audio recordings (Orthoptera spp.). In addition, we surveyed coyotes via camera traps. We deployed camera traps (HyperFire 2, Reconyx, Holmen, USA) during July-October 2018 and May-September 2019, at 65 sites in 2018 (406 camera stations) and 142 sites in 2019 (852 camera stations), with 3-6 cameras set $250-400 \mathrm{~m}$ apart at each survey site for 3-6 weeks. Sites were resampled 2-3 times per year. In total, we collected data for 29,284 camera-trap nights 


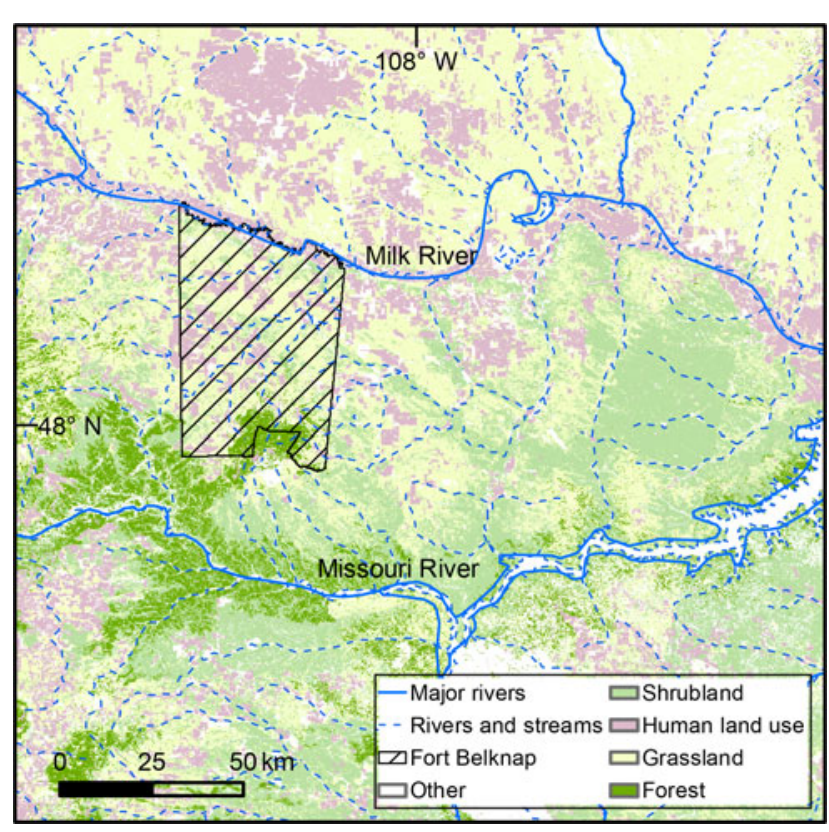

FIG. 2 Landcover in the proposed reintroduction region between the Missouri and Milk Rivers.

$(10,752$ in 2018 and 18,532 in 2019). Cameras were set $50 \mathrm{~cm}$ above ground, facing north to avoid false triggers. Images were sorted, identified to species and stored in the eMammal repository (Shamon, 2021). We collected data at each camera location to assess detection bias: per cent vegetation cover (ground, grasses, forbs, shrubs and canopy), and mean shrub height within a 5-m radius circle in front of each camera, the distance at which the camera sensor was triggered in response to an approaching person, and whether or not the camera was set on an animal trail.

We used track plates to estimate the probability of occurrence of rodent species (Zielinski, 1995; Wiewel et al., 2007; Hacker et al., 2016). We placed 299 track plates at 67 grassland sites, with 2-3 track plates set 250-400 $\mathrm{m}$ apart at each site for 1 week, and each site was sampled twice during May-September 2019. Plates were placed $>100 \mathrm{~m}$ from dirt roads, and baited with food (dry cat food and peanuts); 279 track plates were retrieved intact. Tracks were identified to species using field guides (Eder, 2001; Elbroch, 2003; Moskowitz, 2010) and validated by a professional track expert (Asaf Ben-David, Tel Aviv University, Tel Aviv, Israel).

We estimated Orthoptera diversity from audio recordings made with AudioMoths, a device that records frequencies up to $384 \mathrm{kHz}$ (Hill et al., 2018). We first determined which hours to include in the analysis by evaluating recordings collected $24 \mathrm{~h} /$ day. We concluded that Orthoptera sounds were most common 3-5 hours after sunrise. This is a time of day when bird species are relatively quiet, enabling us to capture mostly insect sounds (Hutchinson, 2002; Brown \& Handford, 2003). We collected three consecutive 10-minute recordings during each sample day, and extracted the first minute of each recording for analysis. We recorded a total of $>1,500$ hours at 222 locations across the study area (14-15 days per site), from which we analysed 157 hours (9,440 1-minute recordings).

\section{Statistical analysis}

We estimated occupancy for coyote and Leporidae spp. using presence/absence data from spatially and temporally repeated measures (camera-trap images), accounting for type II error (MacKenzie et al., 2002), with the occu function from the unmarked package (Fiske \& Chandler, 2011) in $R$ 3.5.1 (R Core Team, 2018). This hierarchical model comprises both detection and site level functions. We first fitted detection explanatory variables with competing models and selected the best fit detection covariates based on Akaike information criterion (AIC) scores (Burnham \& Anderson, 2002). We then constructed occupancy models with different combinations of site level covariates (Table 2, Supplementary Table 1). Competing models were ranked and selected based on their AIC scores. The top models were extrapolated to the study area and used as covariates in the habitat suitability model.

We modelled rodent species occurrence in response to habitat variables (Table 2), centring each response variable using the scale function in $R$ (R Core Team, 2018). Rodent multivariate data (e.g. data of a number of species) were

TABLE 1 Known swift fox Vulpes velox habitat requirements, with information sources.

\begin{tabular}{lll}
\hline Variable & Attributes & Source \\
\hline Soil texture & Sandy loam, loam, silt-loam, silty-clay loam & $\begin{array}{l}\text { Pruss (1999), Jackson \& Choate (2000), } \\
\text { Harrison (2003), Kintigh \& Andersen (2005) }\end{array}$ \\
Slope & Flat terrain with 0-15\% slope & Zimmerman (1998), Pruss (1999), \\
Shrub cover & $\begin{array}{l}\text { Short grass; avoids areas with high shrub cover } \\
\text { Diet }\end{array}$ & $\begin{array}{l}\text { Opportunistic predators of small mammals (rodents, rabbits, } \\
\text { black-tailed prairie dogs), arthropods (Orthoptera in autumn, }\end{array}$ \\
& $\begin{array}{l}\text { Coleoptera in summer), Lepidoptera in spring } \\
\text { High density of coyotes Canis latrans }\end{array}$ & Zackson \& Choate (2000), Nicholson et al. (2006) \\
Threats & Zimmerman (1998), Pechacek et al. (2000)
\end{tabular}


TABLE 2 Details of explanatory variables used for coyote, Orthoptera, rodent and swift fox models.

\begin{tabular}{llll}
\hline Variable $^{1}$ & Description & Resolution & Source \\
\hline Vegetation $(\mathrm{C}, \mathrm{O}, \mathrm{R}, \mathrm{S})$ & $\begin{array}{l}\text { \% cover of shrubs, bare ground, litter, trees, } \\
\text { sagebrush Salvia spp., big sagebrush }\end{array}$ & $30 \mathrm{~m}$ & Xian et al. (2015) \\
& Artemisia tridentata \& annual herbs & & \\
Soil bulk density $(\mathrm{O}, \mathrm{R})$ & Fine earth $10 \times \mathrm{kg} / \mathrm{m}^{3}$ & $250 \mathrm{~m}$ & Hengl (2018a) \\
Clay content $(\mathrm{O}, \mathrm{R}, \mathrm{S})$ & $\%(\mathrm{~kg} / \mathrm{kg})$ & $250 \mathrm{~m}$ & Hengl (2018b) \\
Sand content $(\mathrm{O}, \mathrm{R}, \mathrm{S})$ & $\%(\mathrm{~kg} / \mathrm{kg})$ & $250 \mathrm{~m}$ & Hengl (2018c) \\
Elevation \& slope $(\mathrm{C}, \mathrm{O}, \mathrm{R}, \mathrm{S})$ & $\mathrm{m}, \%$ & $30 \mathrm{~m}$ & Gesch et al. (2002) \\
Human disturbance index $(\mathrm{C}, \mathrm{O}, \mathrm{R}, \mathrm{S})$ & Range $0-4,314$, with 0 being undisturbed & $30 \mathrm{~m}$ & Montana Natural Heritage \\
& natural habitat & & Program (2016) \\
\hline
\end{tabular}

${ }^{1} \mathrm{C}$, coyote; O, Orthoptera; R, rodents; S, swift fox.

modelled in a generalized linear model framework with the binominal distribution using the function manyglm from the mvabund package in $R$ (Wang et al., 2019). We tested and evaluated the response of rodent occurrence to site level covariates using stepwise selection based on AIC scores. We used the function dropi() from the lme 4 package in $R$ (Fang et al., 2013; Bates et al., 2015) to select variables for the final model. The top model was extrapolated over the study region for each rodent species.

We assessed Orthoptera diversity using the bioacoustic index (Boelman et al., 2007), which is the integral sum of the frequencies above the minimum volume of each sound curve (Villanueva-Rivera \& Pijanowski, 2018). We calculated the bioacoustic index for all 9,440 1-minute recordings using the bioacoustic_index function from the soundecology package in $R$ (Boelman et al., 2007; Villanueva-Rivera \& Pijanowski, 2018). Orthoptera species diversity is affected by habitat heterogeneity (Evans, 1988; Weiss et al., 2013) and variation in nutrient availability (Bishop et al., 2010), and insect stridulation (and thereby detectability) is influenced by meteorological variables (Riede, 2017). Therefore, we modelled the values of the bioacoustic index in response to meteorological (Supplementary Table 2) and site level covariates (per cent grass and shrub cover, elevation, slope, and soil composition; Table 2). We extracted meteorological data from the ENV-DATA platform on Movebank (Kranstauber et al., 2011; Dodge et al., 2013). We used linear regression to model the data and performed a stepwise model selection using the $l m$ and stepAIC functions in the MASS package in $R$ (Venables \& Ripley, 2002; Ripley et al., 2019). The final model was extrapolated to the region by fixing all meteorological variables to optimal conditions (zero wind, precipitation and cloud cover, median temperature) and allowing site level covariates to vary.

\section{Habitat suitability models}

We developed and validated a swift fox habitat suitability model using four steps. Firstly, we reviewed variables important for swift fox ecology (Table 1). Secondly, we constructed a habitat suitability model for the swift fox based on remotely-sensed and publicly available geographical interpolated data (Tables $1 \& 2$ ). Variables known to have an inverse relationships with swift fox occurrence were rescaled using an exponential decaying function. Thirdly, we used field surveys to model the distribution of the main prey species of the swift fox, and the occupancy of coyotes (a swift fox predator). We extrapolated the models and created two spatial layers: (1) a threat layer (coyote occupancy), and (2) a resource layer comprising each diet variable (rodents, insects, rabbits) and scaled to o-1. Additional weight was given to rabbit species and ground squirrels Urocitellus richardsonii compared to small rodent species and insects (4:1 respectively) based on known swift fox diet (Table 1). Fourthly, we evaluated the contribution of each of the predictors created in the second and third steps in estimating swift fox habitat suitability. Because of the proximity of an existing swift fox population to the north, it was possible to assess the importance of each of the covariates in relation to known swift fox locations. The model covariates created in step two and three were extrapolated north of the Milk River where the northern swift fox population occurs (Fig. 1).

We obtained 418 known swift fox locations collected during 1997-2017 (Montana Natural Heritage Program, 2019). Known locations were modelled in response to the three covariates using the rspf function from the ResourceSelection package in $R$ (Lele, 2009). Swift fox locations are presenceonly data, and therefore we extracted 10 random points within a $20 \mathrm{~km}^{2}$ buffer around each known location as background points $(4,180$ points in total). The buffer distance was selected based on known swift fox home range estimates in a similar climate (Olson \& Lindzey, 2002). We ran 1,000 iterations of each candidate model. We used multi-model inference to select competing models based on their AIC scores. We used the Hosmer and Lemeshow test to assess model goodness of fit (Hosmer \& Lemeshow, 2000). We then assessed the overlap between the top habitat suitability model based on known swift fox locations and two data layers; remote data and all three covariates combined. The 
TABLE 3 Occupancy models $(\psi)$ for the coyote and Leporidae spp., selected based on AIC rank. Occupancy estimation based on cameratrap data collected during June-October 2018 and May-September 2019 in the Northern Great Plains, Montana, USA (Fig. 1).

\begin{tabular}{|c|c|c|}
\hline Function & Variable & Estimate \pm SE \\
\hline \multicolumn{3}{|l|}{ Coyote } \\
\hline \multirow[t]{3}{*}{ Detection } & $p$ (Intercept) & $-3.584 \pm 0.124$ \\
\hline & $p($ factor $($ trail $))$ & $1.043 \pm 0.127$ \\
\hline & $p$ (shrub cover within $5-\mathrm{m}$ radius) & $-0.005 \pm 0.003$ \\
\hline \multirow[t]{5}{*}{ Occupancy } & $\psi($ Int $)$ & $-0.130 \pm 0.186$ \\
\hline & $\psi($ canopy cover $)$ & $-0.038 \pm 0.013$ \\
\hline & $\psi($ shrub height $)$ & $-0.013 \pm 0.007$ \\
\hline & $\psi($ shrub cover $)$ & $-0.000 \pm 0.011$ \\
\hline & $\psi($ slope $)$ & $0.008 \pm 0.028$ \\
\hline \multicolumn{3}{|c|}{ Leporidae spp. } \\
\hline \multirow[t]{2}{*}{ Detection } & $p$ (Intercept) & $-3.345 \pm 0.134$ \\
\hline & $p$ (factor(trail) $)$ & $1.105 \pm 0.196$ \\
\hline \multirow[t]{5}{*}{ Occupancy } & $\psi($ Intercept $)$ & $-2.208 \pm 0.159$ \\
\hline & $\psi($ canopy cover $)$ & $0.271 \pm 0.122$ \\
\hline & $\psi($ shrub height $)$ & $1.054 \pm 0.423$ \\
\hline & $\psi($ shrub cover $)$ & $-1.924 \pm 0.591$ \\
\hline & $\psi($ slope $)$ & $-0.302 \pm 0.156$ \\
\hline
\end{tabular}

latter is a summation of remote data, resources, and threat layers scaled to o-1. The upper quartile of the swift fox habitat suitability model included values $>0.56$. We used these values as the cutoff to calculate the overlap between data layers.

\section{Results}

\section{Field surveys}

In total we detected coyotes and Leporidae on 521 and 235 occasions, respectively. Coyotes were detected in areas with lower shrub cover and shrub height, and steeper slope (Table 3). Leporidae were detected in areas with lower slope, and higher canopy and shrub cover (Table 3). We identified seven rodent species via tracks on 279 track plates. We modelled the probability of occurrence of the three most prevalent species (Urocitellus richardsonii, Reithrodontomys megalotis, Peromyscus maniculatus), which were detected on 8,67 , and 63 track plates respectively. All candidate rodent models were similar and included \% sand, \% clay, human disturbance index, and soil bulk density (Table 4). Bioacoustic index values were modelled in response to landscape and methodological variables. The top model included four detection covariates (all meteorological) and three site level covariates (\% clay, herbaceous cover and slope; Table 5). The bioacoustics index was positively affected by clay soil content, and negatively affected by \% herbaceous cover (Table 5 ).

\section{Habitat suitability models}

The top habitat suitability model included all three covariates based on field surveys and the remote data (Table 6).
TABLE 4 Estimated occurrence of rodents using a multivariate generalized linear framework, with top model selected using a stepwise process based on AIC scores. Data were collected via track plates during May-September 2019.

\begin{tabular}{lccc}
\hline Variable & Residual df & Deviance & P \\
\hline Rodent community & & & \\
Disturbance index & 299 & 15.029 & 0.005 \\
Soil bulk density & 298 & 9.397 & 0.028 \\
\% sand & 297 & 8.080 & 0.052 \\
\% clay & 296 & 10.757 & 0.008 \\
Individual species models & & \\
Urocitellus richardsonii & & & \\
Intercept & -4.497 & & \\
Disturbance index & 0.555 & 1.261 & 0.289 \\
Soil bulk density & 0.993 & 5.205 & 0.082 \\
\% sand & 1.501 & 1.385 & 0.252 \\
\% clay & 1.414 & 2.772 & 0.140 \\
Reithrodontomys megalotis & & & \\
Intercept & -1.041 & & \\
Disturbance index & 0.285 & 5.486 & 0.057 \\
Soil bulk density & -0.297 & 2.947 & 0.178 \\
\% sand & 0.597 & 2.883 & 0.175 \\
\% clay & 0.506 & 4.075 & 0.140 \\
Peromyscus maniculatus & & & \\
Intercept & -1.406 & & \\
Disturbance index & 0.380 & 8.282 & 0.015 \\
Soil bulk density & 0.142 & 1.245 & 0.253 \\
\% sand & 0.683 & 3.811 & 0.155 \\
\% clay & 0.540 & 3.911 & 0.140 \\
\hline
\end{tabular}

The resources and remote data covariates were positive predictors of swift fox occurrence, and coyote occupancy was a negative predictor of swift fox occurrence (Table 7 , Supplementary Table 1). Overlap between the remote data model (Fig. 3a) and the top swift fox habitat suitability model (Fig. 3d) was 38\% (Fig. 4a), and overlap between the field covariate model and swift fox habitat suitability model was $89 \%$ (Fig. 4 b). The remote data model and top habitat suitability model produced estimates of 4,579 and $5,456 \mathrm{~km}^{2}$ of suitable area, respectively (with suitability

TABLE 5 Bioacoustic index values in response to methodological and site level covariates, with top model selected using a stepwise selection process. Data were collected via audio recordings at grassland sites during May-September 2019.

\begin{tabular}{llrl}
\hline Variable & Estimate \pm SE & $t$ & $\mathrm{P}$ \\
\hline (Intercept) & $-9.80 \pm 5.64 \times 10^{-1}$ & -17.370 & $<0.001$ \\
\% cloud cover & $-6.79 \times 10^{-5} \pm 5.97 \times 10^{-6}$ & -11.382 & $<0.001$ \\
Total & $3.86 \times 10^{1} \pm 9.15 \times 10^{0}$ & 4.214 & $<0.001$ \\
$\quad$ precipitation & & & \\
Wind speed & $1.43 \times 10^{-2} \pm 3.27 \times 10^{-3}$ & 4.382 & $<0.001$ \\
Temperature & $3.53 \times 10^{-2} \pm 1.86 \times 10^{-3}$ & 18.953 & $<0.001$ \\
\% clay & $1.92 \times 10^{-2} \pm 2.74 \times 10^{-3}$ & 7.028 & $<0.001$ \\
\% herb cover & $-3.51 \times 10^{-3} \pm 7.89 \times 10^{-4}$ & -4.452 & $<0.001$ \\
Slope & $-4.14 \times 10^{-3} \pm 2.84 \times 10^{-3}$ & -1.461 & 0.144 \\
\hline
\end{tabular}


TABLE 6 Swift fox habitat suitability models ranked by AIC. Known swift fox locations were modelled in response to a habitat suitability model based on remote data (remote sensing and geographically interpolated data, RD), swift fox diet resources (Resources), and coyote occupancy.

\begin{tabular}{lllrrr}
\hline Model list & Log likelihood & AIC & $\Delta$ AIC & Weight & Goodness of fit $^{1}$ \\
\hline$\sim$ Coyote + Resources + RD & $-2,764.72$ & $5,537.44$ & 0.00 & 0.75 & 0.065 \\
$\sim$ RD + Resources & $-2,766.83$ & $5,539.66$ & 2.23 & 0.25 & 0.416 \\
$\sim$ Coyote + RD & $-2,773.79$ & $5,553.57$ & 16.14 & 0.00 & $<0.001$ \\
$\sim$ RD & $-2,776.14$ & $5,556.28$ & 18.84 & 0.00 & 0.100 \\
$\sim$ Resources & $-2,842.51$ & $5,689.03$ & 151.59 & 0.00 & 0.005 \\
$\sim$ Coyote + Resources & $-2,842.50$ & $5,691.01$ & 153.57 & 0.00 & $<0.001$ \\
$\sim$ Coyote & $-2,866.81$ & $5,737.62$ & 200.18 & 0.00 & $<0.001$ \\
\hline
\end{tabular}

${ }^{1}$ Hosmer and Lemeshow goodness of fit.

considered as values $>0.56$ ). The habitat suitability model containing both field covariates and remote sensing data had a $16 \%$ higher estimated highly suitable area compared to the remote sensing model.

\section{Discussion}

We found that habitat quality variables derived from field surveys improved habitat suitability model predictions for the swift fox. We identified significant differences in estimates of suitable habitat between a model based on remote data and a model that also included habitat quality variables based on field surveys. The differences in the amount of potentially suitable habitat and its distribution highlight how habitat quality variables can greatly impact model predictions, and the limitation of relying solely on remote data. In this case, improved model estimates suggest the reintroduction area can support more individuals, which increases the probability of success (Lewis et al., 2012).

Habitat suitability variables are not necessarily a proxy for habitat quality. Habitat suitability models are defined as the empirical correlation between species occurrence and environmental conditions (Bradley et al., 2012), and those variables that impact species fitness and demographics are indicative of habitat quality (Johnson, 2005). Habitat quality can be measured two ways: (1) by the variation in individual or population demographics, or (2) by the variation

TABLE 7 Swift fox habitat suitability model, with top model selected by a backward stepwise process. Known swift fox locations were modelled in response to three layer products: habitat suitability model based on remotely-sensed data and geographically interpolated data (RD), swift fox diet resources layer, and coyote occupancy layer.

\begin{tabular}{lrrl}
\hline & Estimate $\pm \mathrm{SE}$ & $z$ value & $\mathrm{P}(>|\mathrm{z}|)$ \\
\hline (Intercept) & $-15.36 \pm 1.24$ & -12.39 & $<2 \times 10^{-16}$ \\
Coyote & $-2.15 \pm 0.99$ & -2.17 & 0.03 \\
Resources & $8.86 \pm 1.59$ & 5.56 & $2.75 \times 10^{-8}$ \\
$\mathrm{RD}$ & $5.82 \pm 0.48$ & 12.09 & $<2 \times 10^{-16}$ \\
\hline
\end{tabular}

in environmental conditions that affect habitat selection and fitness (Johnson, 2005). Larson et al. (2004) suggested including habitat quality variables that impact demographics (via population viability analysis) in habitat suitability models. In the case of reintroductions when there is no established population, modelling habitat suitability is only possible through a series of underlying assumptions and model simulations. A third way is to include environment variables indicative of habitat quality (e.g. available resources or predation risk) in habitat suitability models. In reintroductions, the quality of release sites should be assessed beforehand (Cheyne, 2006), but assessment at a local scale may be misleading and may not reflect the quality of the entire landscape. In the case of the swift fox, our approach entails extensive field surveys and additional modelling, to create covariates that represent habitat quality at the landscape level.

Some remote data products are indicative of habitat quality and can be used in specific cases to inform reintroductions. Such products have been shown to increase model accuracy, and combined with their free accessibility they are appealing for such analysis (Bradley et al., 2012). For example, the normalized difference vegetation index is commonly used as a proxy of forage quality for ungulates, or as proxy for insect biomass (Pettorelli et al., 2011; Fernández-Tizón et al., 2020). However, caution should be used when interpreting models based on remote data products, especially for predators that rely on prey densities. For example, throughout their range, swift foxes were eliminated from seemingly suitable habitat as a result of prey depletion and predator persecution (Zimmerman, 1998). In their case the quality of the habitat was compromised even though the vegetation remained intact. Predictive models based on remote data products suggest that there is ample swift fox suitable habitat throughout the species' historic range that is yet to be recolonized (Sovada et al., 2009). Sovada et al. (2009) suggested that swift foxes are not recolonizing these areas for two main reasons: (1) dispersing swift foxes have high mortality rates, and (2) interspecific competition with other meso-canids is hindering recolonizations. Our findings 

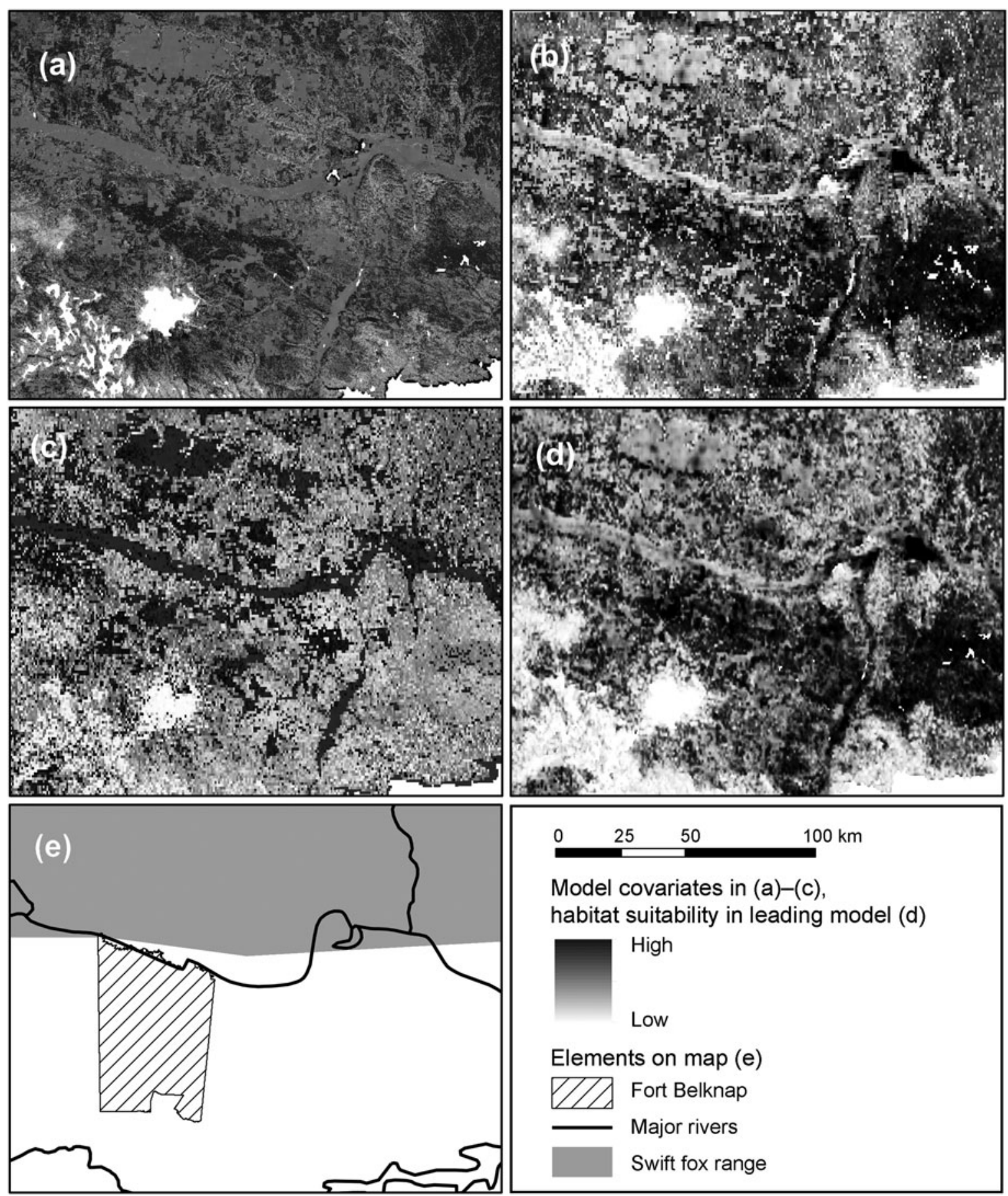

FIG. 3 Swift fox habitat suitability covariates and leading model: (a) habitat suitability based on remote sensing data only, (b) swift fox resources layer, (c) coyote occupancy, (d) swift fox leading habitat suitability model using resource selection function, and (e) the same area, showing the swift fox range, major rivers and Fort Belknap Indian Reservation.

support their hypotheses, and we add that other factors influencing habitat quality, such as resource availability, should be considered. Other studies have found that low prey densities influenced reintroduction success of mesocarnivores (Moehrenschlager et al., 2004; Jachowski et al., 2011; Scrivner et al., 2016; Parsons et al., 2019).

Interspecific competition, as hypothesized by Sovada et al. (2009), cannot be assessed from remote data products.
Predator composition has changed throughout the swift fox's historical range. The coyote is now the largest canid and most abundant mesocarnivore in the Great Plains grasslands (Miller \& Harlow, 2012). Coyotes limit both swift fox and kit fox populations (White \& Garrott, 1997; Kamler et al., 2003), and reintroductions of both species were hindered by competition with coyotes (Moehrenschlager et al., 2004). Kit fox populations increase with high prey densities 

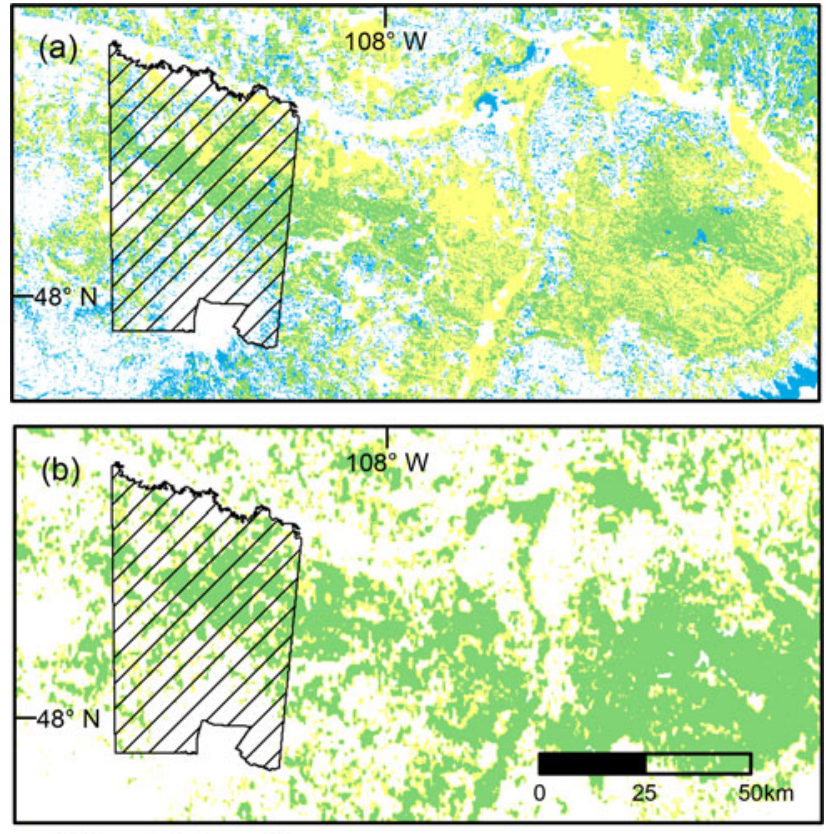

$\square$ (a) Remote data model

$\square$ Habitat suitability model

Overlap of habitat suitability model with (a) remote data model;

(b) remote data and habitat quality variables

$\square$ Fort Belknap

FIG. 4 (a) Overlap between habitat suitability model ( $\sim$ remote data + resources + coyote) and remote data model, and

(b) overlap between habitat suitability model ( $\sim$ remote

data + resources + coyote) and remote data and habitat quality

variables model. Values $>0.56$ (upper quartile of the habitat suitability model) were considered in overlap calculations.

and decrease with high coyote density (Standley et al., 1992; Arjo et al., 2007). However, White \& Garrott (1997) found that predation by coyotes limits kit fox numbers in conjunction with low prey abundance, possibly because increased prey density allowed kit foxes greater dietary breadth and use of dens throughout the year, facilitating coexistence with coyotes (Cypher \& Spencer, 1998). Kamler et al. (2003) found that swift fox population source and sink properties are directly tied to coyote densities and suggested that coyote control can shift swift fox populations from sink to source.

In previous swift fox reintroductions, coyotes were culled to ensure that the fox population was not predated (Honness et al., 2008). However, culling coyotes has only short-term effects on their density, and when coyotes were culled in an area with an established swift fox population it did not affect fox density (KARKI et al., 2007). In other parts of the world, culling was found to be an ineffective method of control for generalist canids that fill a niche similar to coyotes (Baker \& Harris, 2006; Kapota \& Saltz, 2018). The potential negative impact of interspecific competition between swift fox and coyote on reintroduction success warrants assessment of these risks at release sites, and supports the inclusion of variables that affect survival and fitness in habitat suitability assessments.
We did not include people as a potential threat in our analysis because there is no perceived social opposition or risks associated with social tolerance of the swift fox. However, social tolerance can affect fitness of species (Sage, 2019) and ultimately the success of reintroductions. When applicable, we suggest including landscape level assessments of social tolerance, and other gradients of anthropogenic impacts in habitat suitability models used for reintroduction.

In summary, based on our findings and other research, we conclude that including ground-based assessments of habitat quality improves predictions of habitat suitability for reintroductions. The addition of habitat quality data in our case study increased the area predicted to be suitable, and thus the estimated carrying capacity of the landscape. These model outcomes influenced the planning of a swift fox reintroduction led by the Assiniboine and Gros Ventre Tribes of Fort Belknap Indian Reservation.

Acknowledgements We thank the Fort Belknap Indian Community, C.M. Russell Wildlife Refuge, Bureau of Land Management, and the American Prairie Reserve for access to lands; the American Prairie Reserve for providing the space to conduct our research; Justin Kitzes, University of Pittsburgh, for supplying audio recorders; and Asaf Ben-David, Tel Aviv University, for validating track identifications.

Author contributions Study design, fieldwork: all authors; data analysis: HS, ZP; writing: all authors.

\section{Conflicts of interest None.}

Ethical standards This research abided by the Oryx guidelines on ethical standards.

\section{References}

Arjo, W.M., Gese, E.M., Bennett, T.J. \& Kozlowski, A.J. (2007) Changes in kit fox-coyote-prey relationships in the Great Basin Desert, Utah. Western North American Naturalist, 67, 389-401. BAKER, P.J. \& HARRIs, S. (2006) Does culling reduce fox (Vulpes vulpes) density in commercial forests in Wales, UK? European Journal of Wildlife Research, 52, 99-108.

Bates, D., Mächler, M., Bolker, B.M. \& Walker, S.C. (2015) Fitting linear mixed-effects models using lme4. Journal of Statistical Software, 67, 1.

Bishop, J.G., O’Hara, N.B., Titus, J.H., Apple, J.L., Gill, R.A. \& WynN, L. (2010) N-P co-limitation of primary production and response of arthropods to $\mathrm{N}$ and $\mathrm{P}$ in early primary succession on Mount St. Helens Volcano. PLOS ONE, 5, e13598.

Boelman, N.T., Asner, G.P., Hart, P.J. \& Martin, R.E. (2007) Multi-trophic invasion resistance in Hawaii: bioacoustics, field surveys, and airborne remote sensing. Ecological Applications, 17, 2137-2144.

Bradley, B.A., Olsson, A.D., Wang, O., Dickson, B.G., Pelech, L., Sesnie, S.E. \& Zachmann, L.J. (2012) Species detection vs. habitat suitability: are we biasing habitat suitability models with remotely sensed data? Ecological Modelling, 244, 57-64.

BROWN, T.J. \& HANDFORD, P. (2003) Why birds sing at dawn: the role of consistent song transmission. Ibis, 145, 120-129. 
Burnham, K.P. \& Anderson, D.R. (2002) Model Selection and Multimodel Inference: A Practical Information-Theoretic Approach. 2nd edition. Springer-Verlag, New York, USA.

Cheyne, S.M. (2006) Wildlife reintroduction: considerations of habitat quality at the release site. BMC Ecology, 6, 5 .

Cypher, B.L. \& Spencer, K.A. (1998) Competitive interactions between coyotes and San Joaquin kit foxes. Journal of Mammalogy, 79, 204-214.

DANZINGer, L.J. (2011) Using GIS to examine potential wolverine habitat in Colorado: an analysis of habitat fragmentation and wildlife corridors. Papers in Resource Analysis, 13, 1-11.

Dodge, S., Bohrer, G., Weinzierl, R., Davidson, S.C., Kays, R., Douglas, D. et al. (2013) The environmental-data automated track annotation (Env-DATA) system: linking animal tracks with environmental data. Movement Ecology, 1, 1-14.

Dowd, S. (2011) Conservation Assessment and Conservation Strategy for Swift Fox in the United States-2011 Update. South Dakota Department of Game, Fish and Parks, Pierre, USA.

Eder, T. (2001) Animal Tracks of the Great Plains (Animal Tracks Guides). Lone Pine Publishing, Edmonton, Canada.

Elbroch, M. (2003) Mammal Tracks \& Sign: A Guide to North American Species. Stackpole Books, Mechanicsburg, USA.

Evans, W. (1988) Grasshopper (Insecta: Orthoptera: Acrididae) assemblages of tallgrass prairie: influences of fire frequency, topography, and vegetation. Canadian Journal of Zoology, 66, 1495-1501.

Fang, F., Sun, H., Zhao, Q., Lin, C., Sun, Y., GaO, W. et al. (2013) Patterns of diversity, areas of endemism, and multiple glacial refuges for freshwater crabs of the genus Sinopotamon in China (Decapoda: Brachyura: Potamidae). PLOS ONE, 8, e53143.

Fernández-Tizón, M., Emmenegger, T., Perner, J. \& Hahn, S. (2020) Arthropod biomass increase in spring correlates with NDVI in grassland habitat. The Science of Nature, 107, 42.

Fiske, I.J. \& ChANDLER, R.B. (2011) Unmarked: an $R$ package for fitting hierarchical models of wildlife occurrence and abundance. Journal of Statistical Software, 43, 1-23.

Gesch, D., Oimoen, M., Greenlee, S., Nelson, C., Steuck, M. \& Tyler, D. (2002) The National Elevation Dataset. Photogrammetric Engineering and Remote Sensing, 68, 5-11.

Gil-Sánchez, J., Arenas-Rojas, R., Garcia-Tardio, M., Rodriguez-Siles, J. \& Simon-Mata, M.A. (2011) Habitat assessment to select areas for reintroduction of the Endangered Iberian Lynx. Wildlife Biology in Practice, 7, 1-19.

Hacker, K.P., Minter, A., Begon, M., Diggle, P.J., Serrano, S., REIS, M.G. et al. (2016) A comparative assessment of track plates to quantify fine scale variations in the relative abundance of Norway rats in urban slums. Urban Ecosystems, 19, 561-575.

HARrison, R.L. (2003) Swift fox demography, movements, denning, and diet in New Mexico. Southwestern Association of Naturalists, 48, 261-273.

HayWARD, M.W. \& Somers, M.J. (2009) Reintroduction of Top-Order Predators. Blackwell Publishing, Chichester, UK.

Hengl, T. (2018a) Soil bulkdensity (fine earth) $10 \times \mathrm{kg} / \mathrm{m}$-cubicat 6 standard depths $(0,10,30,60,100$ and $200 \mathrm{~cm})$ at 250 m resolution (Version vo2). dx.doi.org/10.5281/zenodo.1475970 [accessed 18 October 2019].

Hengl, T. (2018b) Clay content in \% ( $\mathrm{kg} / \mathrm{kg})$ at 6 standard depths $(0,10$, $30,60,100$ and $200 \mathrm{~cm}$ ) at $250 \mathrm{~m}$ resolution. dx.doi.org/10.5281/ zenodo.2525663 [accessed 18 October 2019].

Hengl, T. (2018c) Sand content in \% ( $\mathrm{kg} / \mathrm{kg}$ ) at 6 standard depths (o, $10,30,60,100$ and $200 \mathrm{~cm}$ ) at $250 \mathrm{~m}$ resolution (Version vo.2). dx.doi. org/10.5281/zenodo.2525662 [accessed 18 October 2019].

Hill, A.P., Prince, P., Piña Covarrubias, E., Doncaster, C.P., Snaddon, J.L. \& Rogers, A. (2018) Audiomoth: evaluation of a smart open acoustic device for monitoring biodiversity and the environment. Methods in Ecology and Evolution, 9, 1199-1211.
Honness, K., Phillips, M. \& Kunkel, K. (2008) Swift Fox Restoration in West Central South Dakota. U.S. Fish \& Wildlife Service, Region 6 Private Stewardship Grants Program Final Progress Report (2003-2007) (FWS Agreement No. 1448-60181$\left.{ }_{3} \mathrm{G}_{53} 8\right)$. Turner Endangered Species Fund, Bozeman, USA.

Hosmer, D.W. \& Lemeshow, S. (200o) Applied Logistic Regression. John Wiley \& Sons, New York, USA.

Hutchinson, J.M.C. (2002) Two explanations of the dawn chorus compared: how monotonically changing light levels favour a short break from singing. Animal Behaviour, 64, 527-539.

IUCN/SSC (Species Survival Commission) (2013) Guidelines for Reintroductions and Other Conservation Translocations. Version 1.o. IUCN, Gland, Switzerland. iucn.org/content/guidelinesreintroductions-and-other-conservation-translocations [accessed 9 July 2021].

Jachowski, D.S., Gitzen, R.A., Grenier, M.B., Holmes, B. \& Millspaugh, J.J. (2011) The importance of thinking big: large-scale prey conservation drives black-footed ferret reintroduction success. Biological Conservation, 144, 1560-1566.

JACKson, V.L. \& ChOATE, J.R. (200o) Dens and den sites of the swift fox, Vulpes velox. Southwestern Association of Naturalists, 45, 212-220.

Johnsingh, A.J.T. \& Madhusudan, M.D. (2009) Tiger reintroduction in India: conservation tool or costly dream? In Reintroduction of Top-Order Predators (eds M.W. Hayward \& M.J. Somers), pp. 146-163. Blackwell, Oxford, UK.

Johnson, M.D. (2005) Habitat quality: a brief review for wildlife biologists. Transactions of the Western Section of the Wildife Society, 41, 31-41.

Kamler, J.F., Ballard, W.B., Gilliland, R.L., Lemons, P.R. \& Mоте, K. (2003) Impacts of coyotes on swift foxes in northwestern Texas. The Journal of Wildlife Management, 67, 317-323.

KA ротA, D. \& SALtZ, D. (2018) Unequal density dependence between survival and recruitment affects harvesting effectiveness. The Journal of Wildife Management, 82, 1756-1766.

Karki, S.M., Gese, E.M. \& Klavetter, M.L. (2007) Effects of coyote population reduction on swift fox demographics in Southeastern Colorado. The Journal of Wildife Management, 71, 2707-2718.

Kellner, C.J., Brawn, J.D. \& KarR, J.R. (1992) What is habitat suitability and how should it be measured? In Wildlife 2001: Populations (eds D.R. McCullough \& R.H. Barrett), pp. 476-488. Springer, Dordrecht, The Netherlands.

Kintigh, K.M. \& Andersen, M.C. (2005) A den-centered analysis of swift fox (Vulpes velox) habitat characteristics in Northeastern New Mexico. The American Midland Naturalist, 154, 229-239.

Kranstauber, B., Cameron, A., Weinzerl, R., Fountain, T., Tilak, S., Wikelski, M. \& Kays, R. (2011) The Movebank data model for animal tracking. Environmental Modelling \& Software, $26,834-835$.

Larson, M.A., Thompson, F.R., Millspaugh, J.J., Dijak, W.D. \& SHIfLEY, S.R. (2004) Linking population viability, habitat suitability, and landscape simulation models for conservation planning. Ecological Modelling, 180, 103-118.

LELE, S.R. (2009) A new method for estimation of resource selection probability function. The Journal of Wildlife Management, 73, 122-127.

Lewis, J.C., Powell, R.A. \& Zielinski, W.J. (2012) Carnivore translocations and conservation: insights from population models and field data for fishers (Martes pennanti). PLOS ONE, 7, e32726.

MacKenzie, D., Nichols, J. \& Lachman, G. (2002) Estimating site occupancy rates when detection probabilities are less than one. Ecology, 83, 2248-2255.

Manlick, P.J., Woodford, J.E., Zuckerberg, B. \& Pauli, J.N. (2017) Niche compression intensifies competition between reintroduced American martens (Martes americana) and fishers (Pekania pennanti). Journal of Mammalogy, 98, 690-702. 
Marks, R., Pauline, R., Rewa, C., Peak, M., Hoagland, J.W., Sovada, M. \& Carbyn, L. (2005) Swift fox (Vulpes velox). Fish and Wildlife Habitat Management Leaflet, 1-8. The Natural Resources Conservation Service, Washington, DC, and Wildlife Habitat Council, Silver Spring, USA. nrcs.usda.gov/Internet/FSE_ DOCUMENTS/nrcseprd1326447.pdf [accessed 9 July 2021].

McCarthy, M.A., Armstrong, D.P. \& Runge, M.C. (2012) Adaptive management of reintroduction. In Reintroduction Biology: Integrating Science and Management (eds J.G. Ewen,

D.P. Armstrong, K.A. Parker \& P.J. Seddon), 256-289. Wiley-Blackwell Hoboken, USA.

Miller, B. \& Harlow, H. (2012) Trophic cascades linking wolves (Canis lupus), coyotes (Canis latrans), and small mammals. Journal of Zoology, 78, 70-78.

Moehrenschlager, A., Cypher, B.L., Ralls, K., List, R. \& Sovada, M.A. (2004) Swift and kit foxes. In The Biology and Conservation of Wild Canids (eds D.W. MacDonald \& C. Sillero-Zubiri), pp. 185-198. Oxford University Press, Oxford, UK.

Moehrenschlager, A. \& Sovada, M. (2016) Vulpes velox. In The IUCN Red List of Threatened Species 2016. dx.doi.org/10.2305/IUCN. UK.2016-3.RLTS.T23059A57629306.en [accessed 18 January 2021].

Moskowitz, D. (2010) Wildlife of the Pacific Northwest: Tracking and Identifying Mammals, Birds, Reptiles, Amphibians, and Invertebrates. Timber Press, Portland, USA.

Montana Natural Heritage Program (2016) Human Disturbance Index. ftpgeoinfo.msl.mt.gov/Data/Spatial/NonMSDI/ Raster/MTHumanDisturbanceIndex.zip [accessed 13 September 2019]

Montana Natural Heritage Program (2019) Observations of Small Mammals in Northeastern Montana. mtnhp.org [accessed 16 September 2019].

Nicholson, K.L., Ballard, W.B., Surles, J., Kamler, J.F. \& Lemons, P.R. (2006) Swift fox use of black-tailed prairie dog towns in Northwest Texas. Journal of Wildlife Management, 70, 1659-1666.

Olson, T.L. \& Lindzey, F.G. (2002) Swift fox survival and production in Southeastern Wyoming. Journal of Mammalogy, 83, 199-206.

Parsons, M.A., Lewis, J.C., Gardner, B., Chestnut, T., Ransom, J.I., Werntz, D.O. \& Prugh, L.R. (2019) Habitat selection and spatiotemporal interactions of a reintroduced mesocarnivore. Journal of Wildlife Management, 83, 1172-1184.

Pechacek, P.E., Lindzey, F.R.G. \& Anderson, S.T.H. (2000) Autumn and winter diet of the swift fox (Vulpes velox) in south-eastern Wyoming. Hystrix, 11, 83-87.

Pettorelli, N., Ryan, S., Mueller, T., Bunnefeld, N., Jedrzejewska, B., Lima, M. \& Kausrud, K. (2011) The Normalized Difference Vegetation Index (NDVI): unforeseen successes in animal ecology. Climate Research, 46, 15-27.

Pruss, S.D. (1999) Selection of natal dens by the swift fox (Vulpes velox) on the Canadian prairies. Canadian Journal of Zoology, $77,646-652$

R Core Team (2018) R: A Language and Environment for Statistical Computing. R Foundation for Statistical Computing, Vienna, Austria. R-project.org [accessed 9 July 2021].

Riede, K. (2017) Acoustic profiling of Orthoptera: present state and future needs. Journal of Orthoptera Research, 27, 203-215.

Ripley, B., Venables, B., Bates, D.M., Hornik, K., Gebhardt, A. \& FirTh, D. (2019) Support Functions and Datasets for Venables and Ripley's MASS, Version 7.3-51.4, 1-169. packages.renjin.org/ package/org.renjin.cran/MASS/7.3-51.4 [accessed September 2021].

Ripple, W.J., Estes, J.A., Beschta, R.L., Wilmers, C.C., Ritchie, E.G., Hebblewhite, M. et al. (2014) Status and ecological effects of the world's largest carnivores. Science, 343, 1241484.
S A GE, A. (2019) Integrating Social Dimensions into Spatial Connectivity Planning for Grizzly Bears. Boise State University, Boise, USA.

Scrivner, J.H., O'Farrell, T.P., Hammer, K. \& Cypher, B.L. (2016) Translocation of the endangered San Joaquin kit fox, Vulpes macrotis mutica: a retrospective assessment. Western North American Naturalist, 76, 90-100.

Smeeton, C. \& Weagle, K. (2000) The reintroduction of the swift fox Vulpes velox to South Central Saskatchewan, Canada. Oryx, $34,171-179$.

Shamon, H. (2021) Smithsonian Grassland Ecology. Camera trap data collected in 2018 and 2019. Montana, USA. eMammal, doi.org/10. 25571/9G7Y-E537 [accessed September 2021].

Smith, J.B., Nielsen, C.K. \& Hellgren, E.C. (2016) Suitable habitat for recolonizing large carnivores in the midwestern USA. Oryx, 50, 555-564.

Sovada, M.A., Woodward, R.O. \& IgL, L.D. (2009) Historical range, current distribution, and conservation status of the Swift Fox, Vulpes velox, in North America. Canadian Field Naturalist, $123,346-367$.

Standley, W.G., Berry, W.H., O’Farrell, T.P. \& Kato, T.T. (1992) Mortality of San Joaquin Kit Fox (Vulpes velox macrotis) at Camp Roberts Army National Guard Training Site, California (No. EGG-10617-2157). EG and G Energy Measurements, Goleta, USA.

TAck, J.D., Jakes, A.F., Jones, P.F., Smith, J.T., Newton, R.E., MARTIN, B.H. et al. (2019) Beyond protected areas: private lands and public policy anchor intact pathways for multi-species wildlife migration. Biological Conservation, 234, 18-27.

Venables, W.N. \& Ripley, B.D. (2002) Modern Applied Statistics with S-Plus. Springer-Verlag, New York, USA.

Villanueva-Rivera, L.J. \& Pijanowski, B.C. (2018) Package 'soundecology'. cran.r-project.org/web/packages/soundecology/ soundecology.pdf [accessed 18 January 2021].

Wang, Y., Naumann, U., Eddelbuettel, D., Wilshire, J., Warton, D., Byrnes, J. et al. (2019) Package 'mvabund'. cran.rproject.org/web/packages/mvabund/mvabund.pdf [accessed 18 January 2021].

Weiss, N., Zucchi, H. \& Hochkirch, A. (2013) The effects of grassland management and aspect on Orthoptera diversity and abundance: site conditions are as important as management. Biodiversity and Conservation, 22, 2167-2178.

White, P.J. \& Garrott, R.A. (1997) Factors regulating kit fox populations. Canadian Journal of Zoology, 75, 1982-1988.

Wiewel, A.S., Clark, W.R. \& Sovada, M.A. (2007) Assessing small mammal abundance with track-tube indices and mark-recapture population estimates. Journal of Mammalogy, 88, 250-260.

Xian, G., Homer, C., Rigge, M., Shi, H. \& Meyer, D. (2015) Characterization of shrubland ecosystem components as continuous fields in the northwest United States. Remote Sensing of Environment, 168, 286-300.

Zielinski, W.J. (1995) Track plates. In American Marten, Fisher, Lynx, and Wolverine: Survey Methods for Their Detection (eds W.J. Zielinski \& T. Kucera), pp. 67-86. U.S. Department of Agriculture, Forest Service, Pacific Southwest Research Station, Albany, USA.

Zielinski, W.J., Dunk, J.R., Yaeger, J.S. \& LaPlante, D.W. (2010) Developing and testing a landscape-scale habitat suitability model for fisher (Martes pennanti) in forests of interior northern California. Forest Ecology and Management, 260, 1579-1591.

Zimmerman, A. (1998) Reestablishment of swift fox in north central Montana. MSc thesis, Montana State University, Bozeman, USA. 